\title{
Changes in Air Quality during the First-Level Response to the Covid-19 Pandemic in Shanghai Municipality, China
}

\author{
Yang Bai ${ }^{1,2, *,+}$, Yi Zhou ${ }^{1,2,+}$, Juha M. Alatalo ${ }^{3 \oplus}$ and Alice C. Hughes ${ }^{1,2}$ \\ 1 Center for Integrative Conservation, Xishuangbanna Tropical Botanical Garden, Chinese Academy of Sciences, \\ Menglun 666303, China; zhouyi@xtbg.ac.cn (Y.Z.); ach_conservation@hotmail.com (A.C.H.) \\ 2 Center of Conservation Biology, Core Botanical Gardens, Chinese Academy of Sciences, \\ Mengla 666303, China \\ 3 Environmental Science Center, Qatar University, Doha 2713, Qatar; jalatalo@qu.edu.qa \\ * Correspondence: baiyang@xtbg.ac.cn \\ + Yang Bai and Yi Zhou contributed equally to this manuscript.
}

Received: 25 September 2020; Accepted: 23 October 2020; Published: 26 October 2020

\begin{abstract}
Ongoing rapid urban population growth world-wide has led to serious environmental problems that affect ecosystems and also lower the security and happiness of urban residents about their living environment. The most frequently reported negative impact is a deterioration in urban air quality. In this study, we performed a comprehensive assessment of the effects of the city lockdown policy in response to Covid-19 on air quality in Shanghai Municipality, China, and sought to identify a balance point between human activities and improving air quality. The first-level response (FLR) by Shanghai to control the spread of Covid-19 was to launch a lockdown, which remained in place from 24 January to $23 \mathrm{March}$, 2020. We compared airborne pollutant concentrations in different regions (downtown, suburbs) of Shanghai city in three periods (Pre-FLR, During-FLR, and Post-FLR) and in the corresponding periods in the previous year. The results showed that air quality improved significantly During-FLR compared with Pre-FLR, with the concentrations of $\mathrm{PM}_{2.5}, \mathrm{PM}_{10}, \mathrm{SO}_{2}, \mathrm{NO}_{2}$, and $\mathrm{CO}$ all decreasing significantly. The concentrations of all pollutants except $\mathrm{O}_{3}$ also decreased significantly compared with the same period in the previous year. There were also some differences in pollutant concentrations between the downtown region and the suburbs of Shanghai. However, we found that the concentrations of pollutants rebounded gradually when the restrictions on human activities ended after two months of lockdown. This study provides empirical evidence of the important effect of limiting human activities on air quality. For sustainable and clean future urban management in Shanghai and beyond, central government policy regulations requiring a low-carbon lifestyle and cleaner production in industries should be established.
\end{abstract}

Keywords: COVID-19; air quality; air pollutant; emission

\section{Introduction}

The urbanization rate has exceeded 50\% world-wide and in China since 2010, and the rate is predicted to increase further in coming decades [1]. Thus, by 2050, over 70\% of the world's population will live in cities and the megacities of Asia are likely to experience 90\% population growth by 2050 [2]. Rapid population growth, compounded by unregulated urban sprawl and industrialization, has led to serious environmental problems, affecting global ecosystems and the security, health, and happiness of urban residents $[3,4]$. The most frequently reported consequence of ongoing urbanization is a deterioration in air quality $[2,5,6]$. Studies have demonstrated that the main sources of urban air pollution are vehicles and human activities [7]. However, more empirical evidence 
on the effects of vehicular traffic and human activities is needed for better targeting of countermeasures in urban management.

Cities world-wide have been severely affected by the COVID-19 epidemic, which to date (10 August 2020) has resulted in over 20 million infections and 700,000 deaths. Most governments at all levels took quick actions to prevent the rapid spread of this virus and many countries and cities have made important progress in containing the virus, such as Italy, Germany, Spain, and China [8,9]. In Shanghai, one of the great mega-cities in China, the municipal government launched a first-level response (FLR, or 'lockdown') policy for the major public health emergency on 24 January 2020. Under this policy, people were required to stay at home, most workplaces and all public places were closed, including public libraries, art galleries, museums, amusement parks, scenic spots; and large public events were canceled.

The FLR policy had a very positive effect in controlling the epidemic, but may also have had a significant effect in improving urban air quality [2]. It has been reported that the air quality in Barcelona improved during lockdown, with significant decreases in the concentrations of several pollutants [10]. However, more practical evidence is needed to confirm the effect of lockdown policy on urban air quality, before examining the possibility of adopting such alternative actions within urban air quality management.

Although the COVID-19 epidemic has had unfortunate consequences for all of humanity, it provides a rare opportunity to study the effects of city lockdown on urban air quality. The overall aim of the present study was to evaluate urban air quality during lockdown, compared with before and after, using the case of Shanghai, China, in order to determine the effect of reduced human activities on air quality. Specific objectives of the study were to compare differences in air pollutant concentrations in Shanghai: (1) Before, during, and after the FLR period; (2) in these periods compared with the corresponding periods in the previous year; and (3) in downtown Shanghai and in the suburbs during the FLR. The intention was to provide policymakers with empirical evidence of the importance of environmental policies and with decision support for further urban adaptive management to achieve air quality improvements.

\section{Study Area}

Shanghai is located between $30^{\circ} 40^{\prime}-31^{\circ} 53^{\prime} \mathrm{N}$ and $120^{\circ} 52^{\prime}-122^{\circ} 12^{\prime} \mathrm{E}$ on the west coast of the Pacific Ocean and the eastern edge of the Asian continent (Figure 1). In 2019, the city occupied an area of $6340 \mathrm{~km}^{2}$ and had a permanent resident population of 24.28 million [11]. Shanghai is China's international center for the economy, finance, trade, shipping, and technological innovation. Air quality in the city has an important impact on the daily lives of local residents [12]. As an international metropolis, Shanghai has a complete air pollution monitoring system. According to the most recent annual report, fine particulate matter $\left(\mathrm{PM}_{2.5}\right)$ was the main pollutant in 2019, with an annual average concentration of $35 \mu \mathrm{g} / \mathrm{m}^{3}$. Based on air quality index (AQI), the daily good air quality (AQI < 100) rate of Shanghai was $84.4 \%$ in 2019 [13]. 


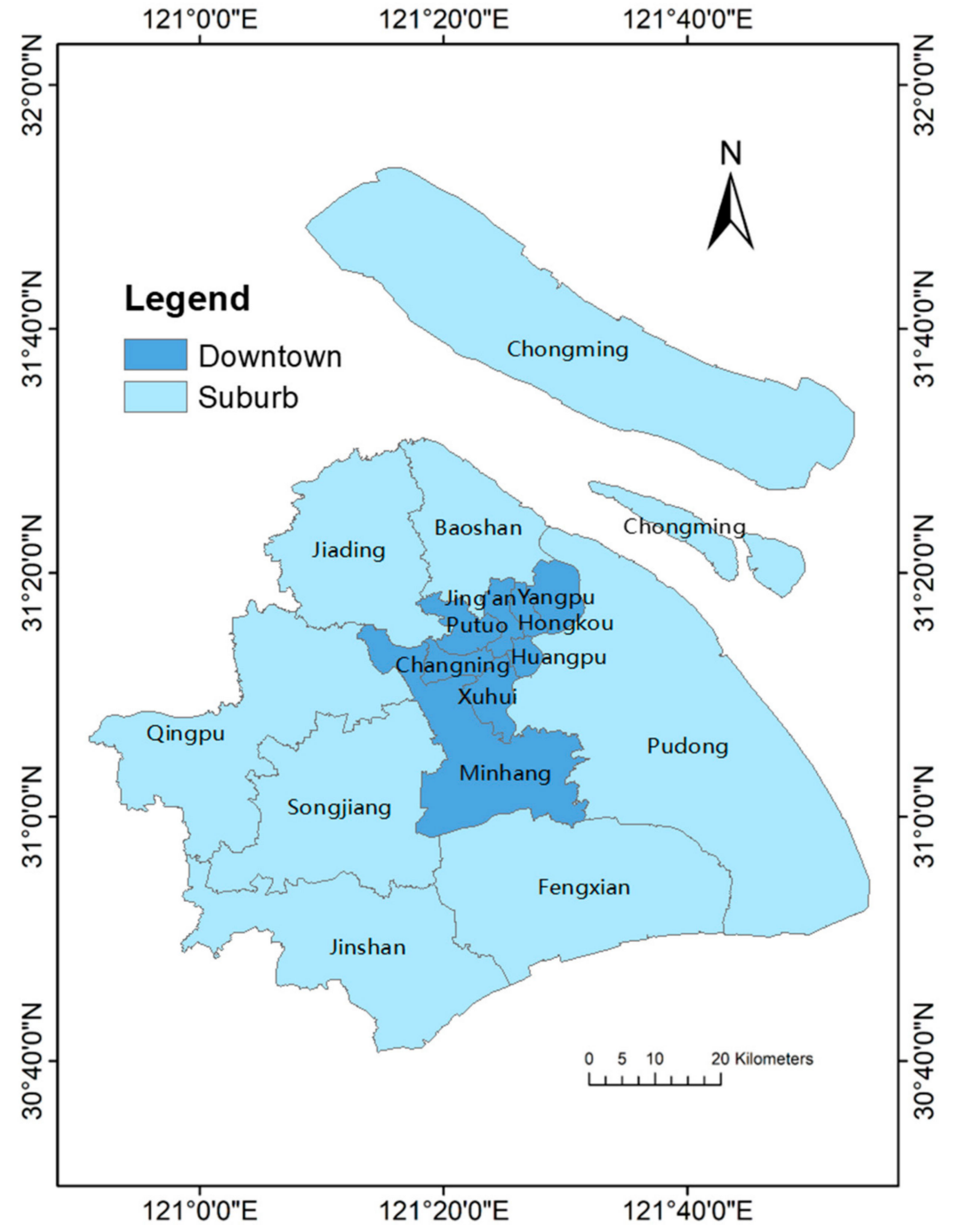

Figure 1. Location of Shanghai's different administrative divisions.

\section{Methods}

\subsection{Selection of Air Quality Indicators}

China released a new air quality assessment standard in March 2012, with the following six pollutants monitored and data updated every hour [14]: Particulate matter with diameter less than $2.5 \mu \mathrm{m}\left(\mathrm{PM}_{2.5}\right)$, particulate matter with diameter less than $10 \mu \mathrm{m}\left(\mathrm{PM}_{10}\right)$, nitrogen dioxide $\left(\mathrm{NO}_{2}\right)$, sulfur dioxide $\left(\mathrm{SO}_{2}\right)$, ozone $\left(\mathrm{O}_{3}\right)$, and carbon monoxide $(\mathrm{CO})$. The AQI value for a Chinese city presents these pollutants in a unified evaluation standard. All six pollutants are harmful to human respiratory health, e.g., researchers have found an association between industrial $\mathrm{PM}_{10}$ and mortality [15] and have shown that air pollution can cause deaths from cardio-respiratory diseases [16]. We selected all six pollutants as air quality indicators when comparing air quality during different FLR periods and in city areas.

\subsection{Data Collection}

Data on the actual daily concentrations of the six indicators in the city of Shanghai in the period 25 November 2019 to 22 May 2020 were downloaded from the website of Shanghai Municipal Bureau of Ecology and Environment (https://sthj.sh.gov.cn/). The data also included daily average values for each of the 16 districts in Shanghai (see Tables S1-S18). 


\subsection{Data Processing and Comparison}

The 180-day monitoring period for which data were obtained was divided into three 60-day periods: Pre-FLR (25 November 2019 to 23 January 2020); during-FLR (24 January to 23 March 2020); and post-FLR (24 March to 22 May 2020). The daily data thus made up a total of 60 samples in each period. For control and data comparison, we also obtained data for the same periods in the previous year. In a spatial comparison, we divided the 16 districts in the city into two groups: Downtown and suburbs (Figure 1). We compared differences in the concentrations of the six pollutants between the Pre-FLR, During-FLR, and Post-FLR periods, between the study periods and the previous year, and between downtown and suburbs in each period.

We used the Wilcoxon Signed Rank Test by SPSS 21 to test for significant differences in each comparison. This non-parametric test was chosen because the data did not show a normal distribution and because comparisons were made between paired sets, which are related samples. The Wilcoxon Signed Rank Test can be used if the differences between pairs of data are non-normally distributed. It compares the sample median against a hypothetical median, applying the null hypothesis that the medians of two samples are equal. Standardized test statistics are produced, based on which decisions are made about the null hypothesis and an alternative hypothesis. Here, we also created box-plots to show data dispersion.

\section{Results}

\subsection{Differences in Pollutant Concentrations in the Pre-, During-, and Post-FLR Periods}

Compared with Pre-FLR, the concentration of all pollutants except $\mathrm{O}_{3}$ was lower During-FLR (Figure 2). For example, the average concentration of $\mathrm{PM}_{2.5}$ declined from $48.9 \mu \mathrm{g} / \mathrm{m}^{3}$ pre-FLR to $33.7 \mu \mathrm{g} / \mathrm{m}^{3}$ during-FLR, while that of $\mathrm{PM}_{10}$ declined from $47.0 \mu \mathrm{g} / \mathrm{m}^{3}$ to $38.3 \mu \mathrm{g} / \mathrm{m}^{3}$, a $31 \%$ and $19 \%$ reduction, respectively. Post-FLR, the average concentration of all pollutants increased again compared with during-FLR. For example, the average concentration of $\mathrm{PM}_{2.5}$ increased to $40.5 \mu \mathrm{g} / \mathrm{m}^{3}$ and that of $\mathrm{PM}_{10}$ to $41.5 \mu \mathrm{g} / \mathrm{m}^{3}$, a $20 \%$ and $8 \%$ increase, respectively.
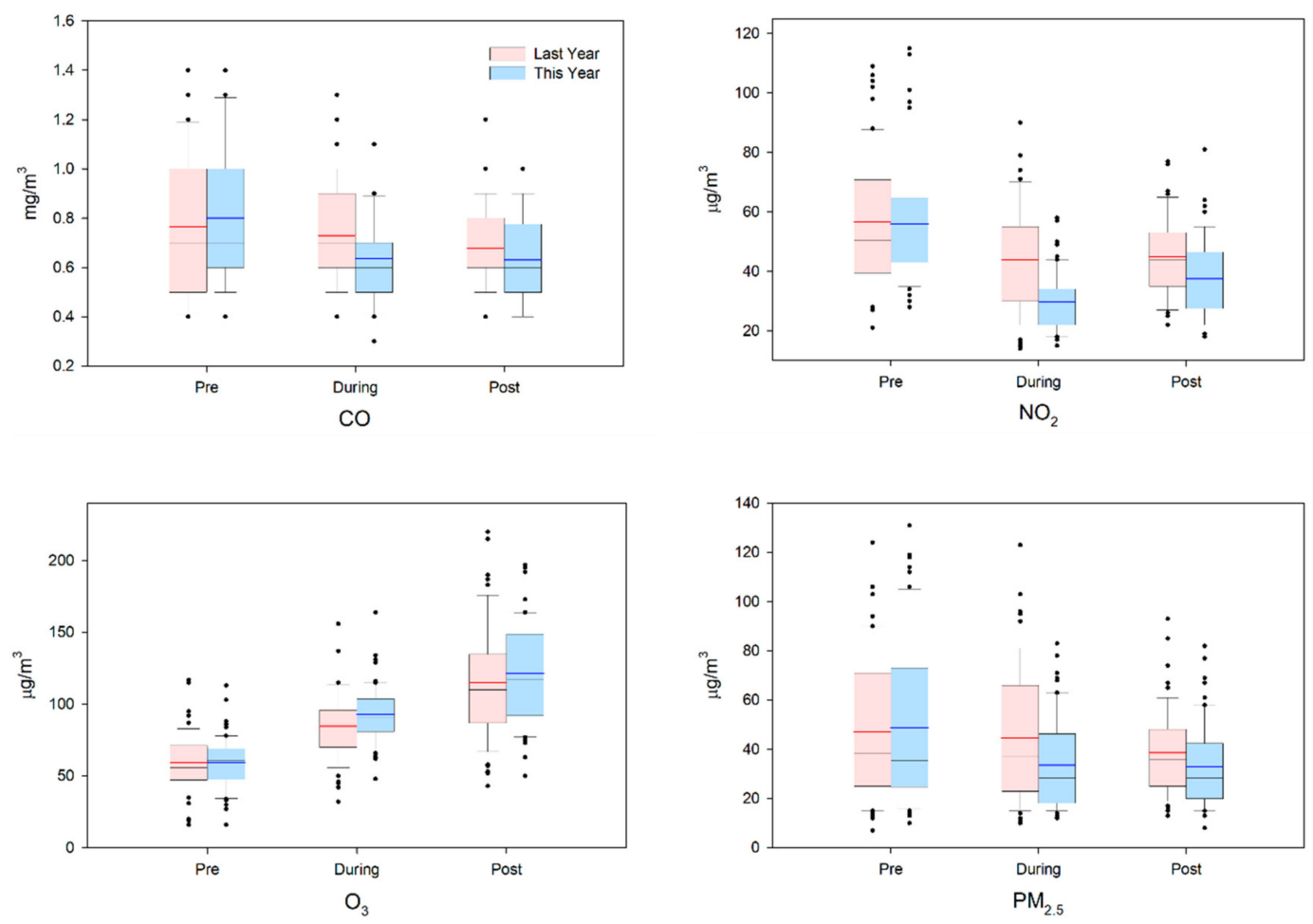

Figure 2. Cont. 

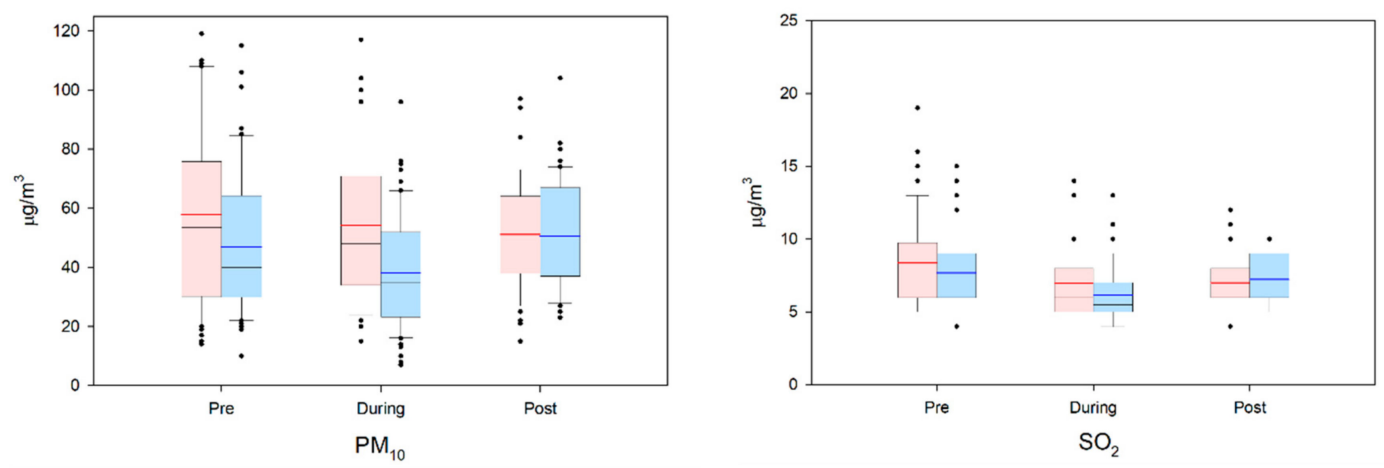

Figure 2. Boxplot of mean daily concentrations of the six pollutants $\left(\mathrm{CO}, \mathrm{NO}_{2}, \mathrm{O}_{3}, \mathrm{PM}_{2.5}, \mathrm{PM}_{10}, \mathrm{SO}_{2}\right)$ in the three study periods (pre-, during-, post-first-level response (FLR)), and in the same periods in the previous year. Red and blue lines indicate mean of different sets of data.

According to the results of Wilcoxon Signed Rank Test and comparison of the average values at each stage, the concentrations of all pollutants but $\mathrm{O}_{3}$ declined significantly, and the concentration of $\mathrm{O}_{3}$ increased significantly, between the pre- and during-FLR periods. However, the concentrations of $\mathrm{NO}_{2}, \mathrm{O}_{3}, \mathrm{PM}_{10}$, and $\mathrm{SO}_{2}$ showed significant increases from during- to post-FLR (Table 1). Between the two periods before and after FLR (pre- and post- periods), the concentrations of $\mathrm{CO}, \mathrm{NO}_{2}$, and $\mathrm{PM}_{2.5}$ showed significant decreases, while the concentration of $\mathrm{O}_{3}$ showed a significant increase (Table 1). The concentrations of $\mathrm{PM}_{10}$ and $\mathrm{SO}_{2}$ both declined, but the differences were not significant.

Table 1. Pair-wise comparison of daily concentrations of each pollutant $\left(\mathrm{CO}, \mathrm{NO}_{2}, \mathrm{O}_{3}, \mathrm{PM}_{2.5}, \mathrm{PM}_{10}\right.$, $\mathrm{SO}_{2}$ ) in the three periods (pre-, during-, post-FLR). Values shown are standardized test statistics of the Wilcoxon Signed Rank Test. * Significant difference $(p<0.05)$ and ${ }^{* *}$ Highly significant difference $(p<0.01)$. (blue $=$ period average concentration decline, red $=$ period average concentration increase, both compared with previous period. The darker the color, the greater the variation).

\begin{tabular}{cccc}
\hline & Pre-During & During-Post & Pre-Post \\
\hline $\mathrm{CO}$ & $-3.602^{* *}$ & $-0.07^{* *}$ & $-3.495^{* *}$ \\
$\mathrm{NO}_{2}$ & $-6.373^{* *}$ & $-3.247^{* *}$ & $-5.035^{* *}$ \\
$\mathrm{O}_{3}$ & $-6.593^{* *}$ & $-4.741^{* *}$ & $-6.729^{* *}$ \\
$\mathrm{PM}_{2.5}$ & $-3.082^{* *}$ & -0.321 & $-2.880^{* *}$ \\
$\mathrm{PM}_{10}$ & $-2.227^{*}$ & $-3.560^{* *}$ & -1.03 \\
$\mathrm{SO}_{2}$ & $-3.291^{* *}$ & $-3.231^{* *}$ & -0.5 \\
\hline
\end{tabular}

\subsection{Differences Compared with Previous Year}

Comparison of the pre-FLR period with the same period in the previous year showed that the concentrations of three pollutants $\left(\mathrm{PM}_{10}, \mathrm{SO}_{2}\right.$, and $\left.\mathrm{NO}_{2}\right)$ were lower, while those of the other three pollutants $\left(\mathrm{PM}_{2.5}, \mathrm{O}_{3}\right.$, and $\left.\mathrm{CO}\right)$ were higher (Figure 2). However, none of the differences was statistically significant.

During-FLR, the concentrations of $\mathrm{PM}_{2.5}, \mathrm{PM}_{10}, \mathrm{SO}_{2}, \mathrm{NO}_{2}$, and $\mathrm{CO}$ all declined significantly, while the concentration of $\mathrm{O}_{3}$ increased significantly, compared with the same period in the previous year (Table 2).

Post-FLR, the concentrations of four pollutants $\left(\mathrm{PM}_{2.5}, \mathrm{PM}_{10}, \mathrm{NO}_{2}\right.$, and $\left.\mathrm{CO}\right)$ decreased compared with the same period in the previous year, while the concentration of $\mathrm{SO}_{2}$ and $\mathrm{O}_{3}$ increased. The differences were significant for $\mathrm{NO}_{2}$ (Table 2). 
Table 2. Daily concentrations of each pollutant $\left(\mathrm{CO}, \mathrm{NO}_{2}, \mathrm{O}_{3}, \mathrm{PM}_{2.5}, \mathrm{PM}_{10}, \mathrm{SO}_{2}\right)$ in the three periods (pre-, during-, post-FLR) compared with those in the same periods in the previous year. Values shown are standardized test statistics of the Wilcoxon Signed Rank Test. ${ }^{*}$ Significant difference $(p<0.05)$ and ** Highly significant difference $(p<0.01)$. (blue = period average concentration decline, red $=$ period average concentration increase, both compared with same periods of the previous year. The darker the color, the greater the variation).

\begin{tabular}{cccc}
\hline & Pre-FLR & During-FLR & Post-FLR \\
\hline $\mathrm{CO}$ & -0.926 & $-2.479^{*}$ & -1.196 \\
$\mathrm{NO}_{2}$ & -0.159 & $-4.500^{* *}$ & $-2.567^{*}$ \\
$\mathrm{O}_{3}$ & -0.25 & $-2.597^{* *}$ & -1.309 \\
$\mathrm{PM}_{2.5}$ & -0.419 & $-2.323^{*}$ & -1.111 \\
$\mathrm{PM}_{10}$ & -1.71 & $-3.775^{* *}$ & -0.396 \\
$\mathrm{SO}_{2}$ & -1.239 & $-2.527^{*}$ & -0.674 \\
\hline
\end{tabular}

\subsection{Differences between Downtown and Suburbs}

Comparisons of mean pollutant concentrations in the downtown area (8 districts, see Figure 1) of Shanghai and the suburbs (eight districts) showed that in the Pre-FLR period, the concentrations of $\mathrm{PM}_{2.5}, \mathrm{PM}_{10}, \mathrm{NO}_{2}$, and $\mathrm{CO}$ were all higher downtown than in the suburbs (Figure 3), and the differences were significant for $\mathrm{NO}_{2}$ and $\mathrm{CO}$ (Table 3). The concentrations of $\mathrm{O}_{3}$ and $\mathrm{SO}_{2}$ were all significantly higher in the suburbs than in the downtown area (Table 3).

Table 3. Pair-wise comparison of daily concentrations of each pollutant $\left(\mathrm{CO}, \mathrm{NO}_{2}, \mathrm{O}_{3}, \mathrm{PM}_{2.5}, \mathrm{PM}_{10}, \mathrm{SO}_{2}\right)$ in the three periods (pre-, during-, post-FLR) between downtown and suburbs of Shanghai Municipality. Values shown are standardized test statistics of the Wilcoxon Signed Rank Test. * Significant difference $(p<0.05)$ and ${ }^{* *}$ Highly significant difference $(p<0.01)$ (blue = period average concentration higher in the suburbs, red = period average concentration higher in the downtown. The darker the color, the higher the average concentration).

\begin{tabular}{cccc}
\hline & Pre-FLR & During-FLR & Post-FLR \\
\hline $\mathrm{CO}$ & $-4.676^{* *}$ & -0.291 & -1.311 \\
$\mathrm{NO}_{2}$ & $-6.736^{* *}$ & $-6.737^{* *}$ & $-6.736^{* *}$ \\
$\mathrm{O}_{3}$ & $-6.475^{* *}$ & $-5.923^{* *}$ & $-6.652^{* *}$ \\
$\mathrm{PM}_{2.5}$ & -0.294 & -1.538 & $-2.998^{* *}$ \\
$\mathrm{PM}_{10}$ & -1.174 & -0.974 & $-2.188^{*}$ \\
$\mathrm{SO}_{2}$ & $-5.193^{* *}$ & $-2.955^{* *}$ & $-6.729^{* *}$ \\
\hline
\end{tabular}
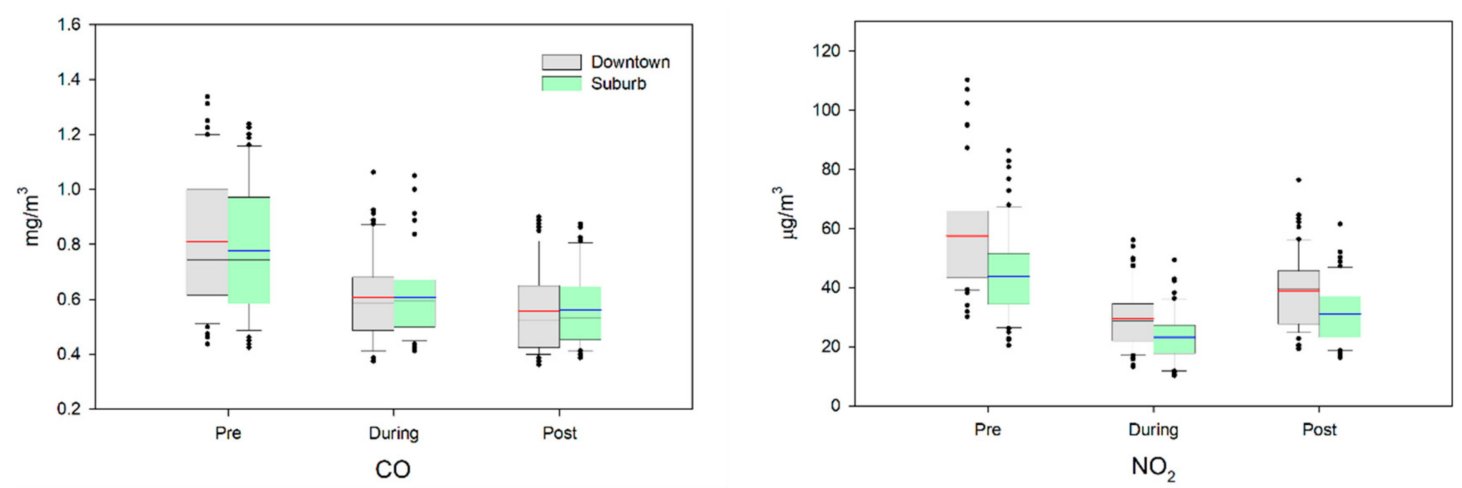

Figure 3. Cont. 

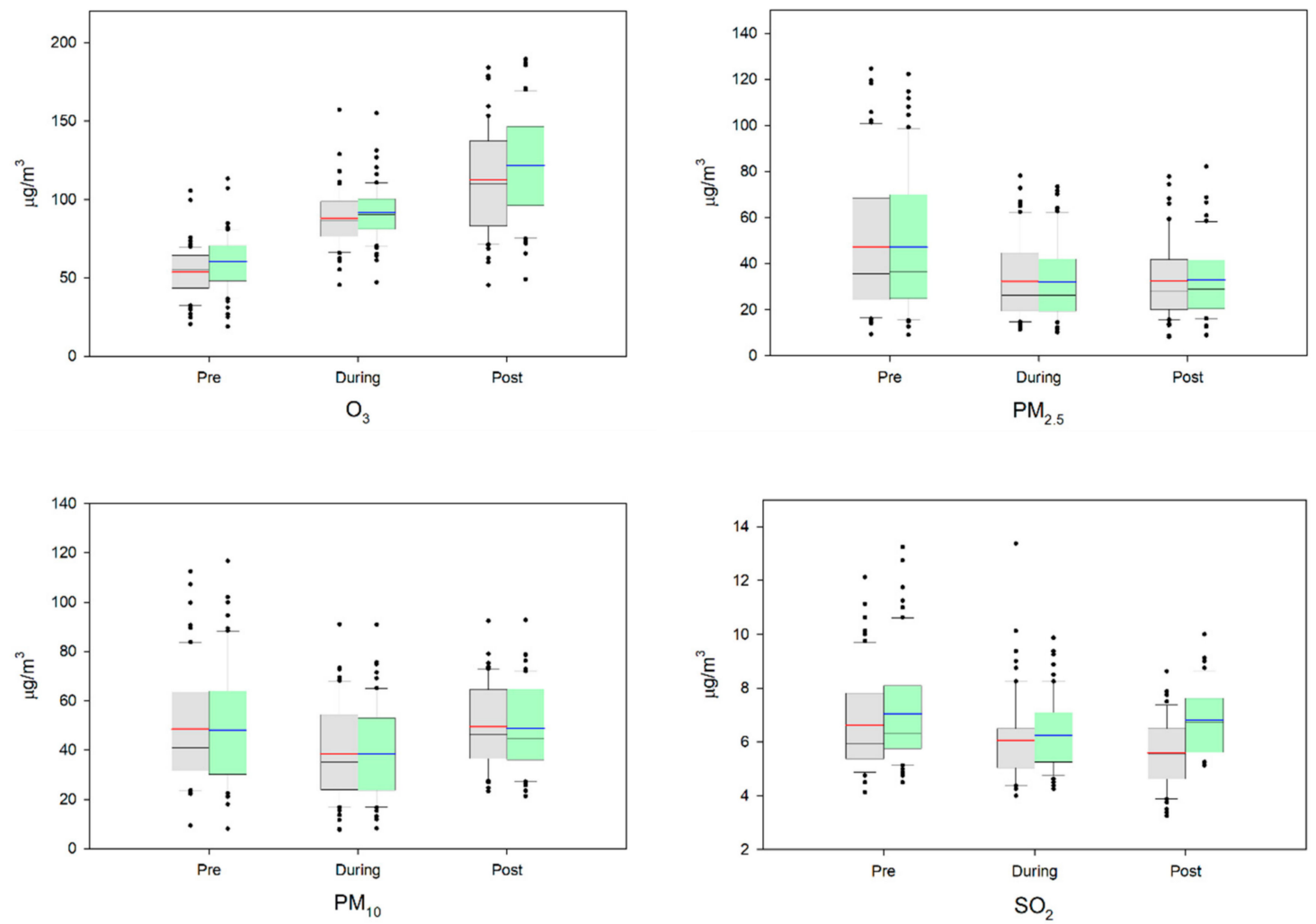

Figure 3. Boxplot of mean daily concentrations of the six pollutants $\left(\mathrm{CO}, \mathrm{NO}_{2}, \mathrm{O}_{3}, \mathrm{PM}_{2.5}, \mathrm{PM}_{10}, \mathrm{SO}_{2}\right)$ in the three periods (pre-, during-, post-FLR) in the downtown and suburbs of Shanghai Municipality. Red and blue lines indicate mean of different sets of data.

During-FLR, the concentrations of three pollutants $\left(\mathrm{PM}_{2.5}, \mathrm{PM}_{10}\right.$, and $\left.\mathrm{NO}_{2}\right)$ were higher downtown (Figure 3), and the difference in concentration was significant for $\mathrm{NO}_{2}$. The concentrations of the other three pollutants $\left(\mathrm{O}_{3}, \mathrm{SO}_{2}\right.$, and $\left.\mathrm{CO}\right)$ were higher in the suburbs, and significantly higher for both $\mathrm{O}_{3}$ and $\mathrm{SO}_{2}$ (Table 3).

Post-FLR, the concentrations of two pollutants $\left(\mathrm{PM}_{10}\right.$ and $\left.\mathrm{NO}_{2}\right)$ were both significantly higher downtown, while the concentrations of the other four pollutants $\left(\mathrm{PM}_{2.5}, \mathrm{O}_{3}, \mathrm{SO}_{2}\right.$, and $\left.\mathrm{CO}\right)$ were higher in the suburbs (Figure 3). The differences were significant for $\mathrm{PM}_{2.5}, \mathrm{O}_{3}$, and $\mathrm{SO}_{2}$ (Table 3).

There was significant spatial variation in each pollutant, particularly in the downtown and suburbs (in total 16 districts, see Figure 1). However, the distribution and change characteristics of different pollutants showed different spatial patterns (Figure 4).
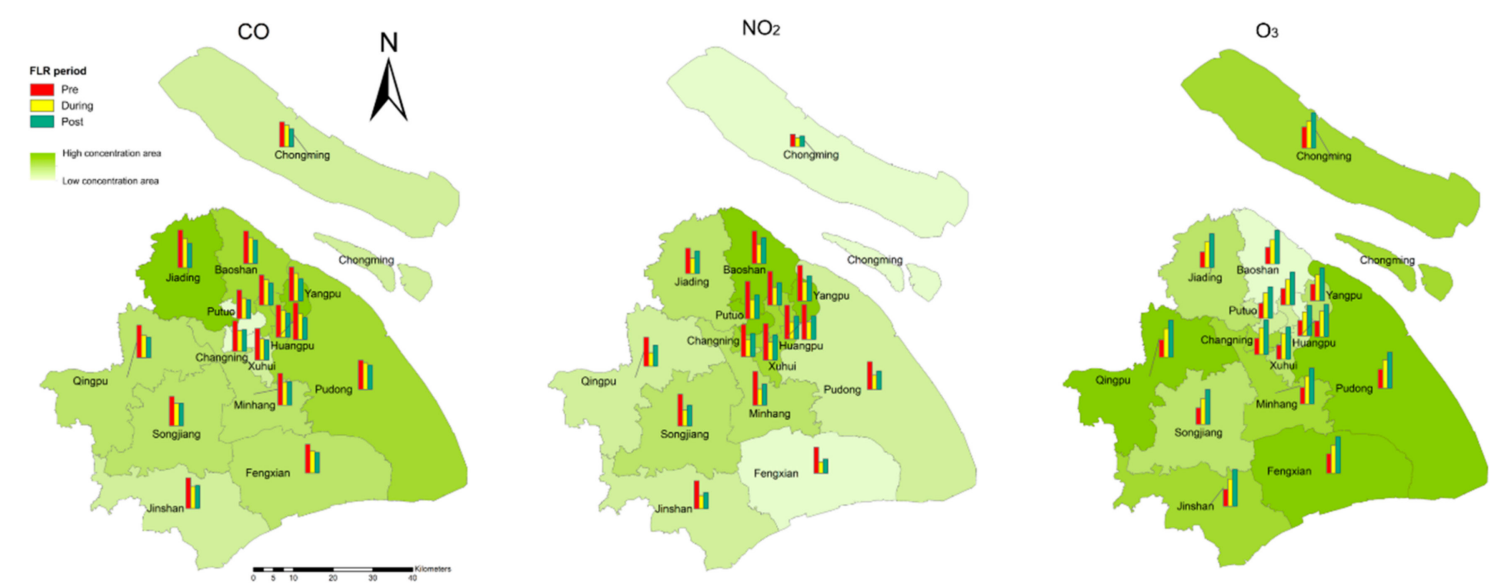

Figure 4. Cont. 

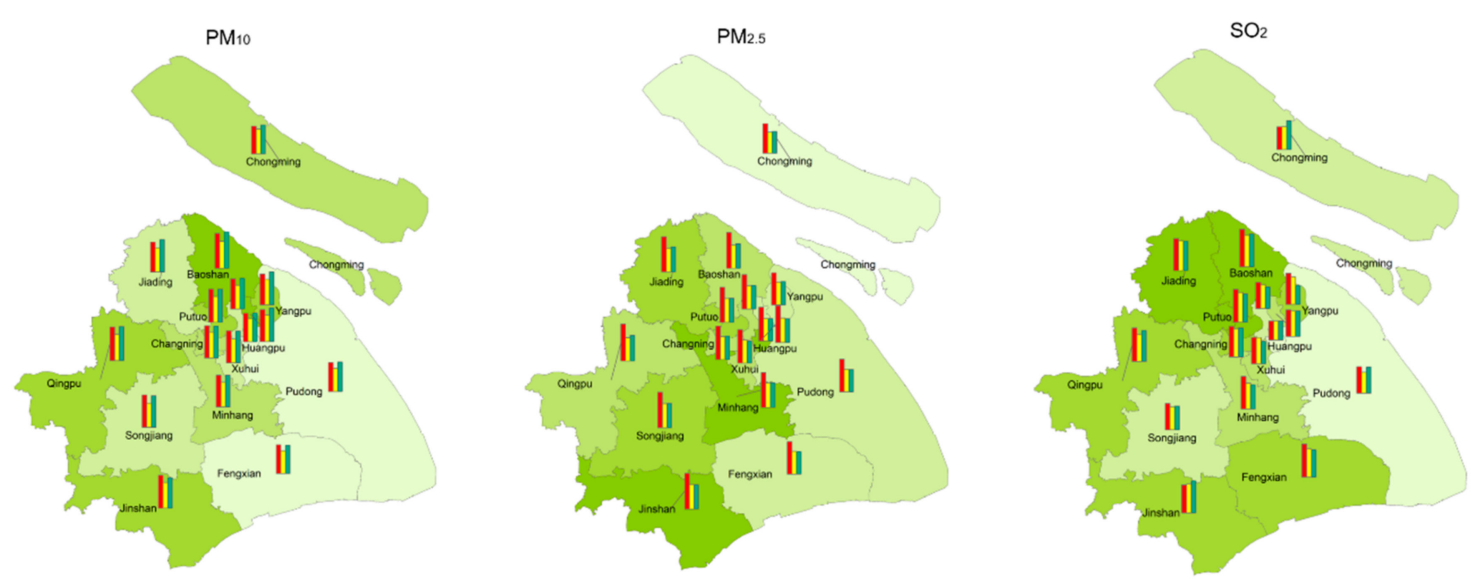

Figure 4. Distribution of average concentration of pollutants in each district of Shanghai Municipality during the three periods (pre-, during-, post-FLR). The color of the base map indicates average pollutant concentration in each district in the during-FLR period, where the darker the color, the higher the concentration. The bar graphs on top of maps show the concentrations in different districts in the three periods.

\section{Discussion}

\subsection{Variation and Driving Factors}

Compared with pre-FLR, the concentrations of all pollutants except $\mathrm{O}_{3}$ declined significantly in the during-FLR period. However, the concentration of almost all pollutants except $\mathrm{O}_{3}$ rebounded in the post-FLR period, although not to the same level (except $\mathrm{O}_{3}$ ) as in pre-FLR. Compared with the corresponding period in the previous year, all pollutants showed no significant difference in pre-FLR. However, during-FLR the concentrations of $\mathrm{PM}_{2.5}, \mathrm{PM}_{10}, \mathrm{SO}_{2}, \mathrm{NO}_{2}$, and $\mathrm{CO}$ all showed significant reductions compared with the same period in the previous year. Even after the FLR ended, the concentrations of some pollutants, such as $\mathrm{PM}_{2.5}, \mathrm{CO}$, and $\mathrm{NO}_{2}$, remained at a lower level than in the corresponding period in the previous year.

These results indicate that the concentrations of all key air quality pollutants considered in this study, except $\mathrm{O}_{3}$, may decline rather rapidly when human activities are restricted. This is consistent with findings in the recent literature that e.g., pollutant concentrations decreased during a partial lockdown in São Paulo state, Brazil [17] and that the 2020 Malaysia Movement Control Order had significant effects in reducing $\mathrm{PM}_{2.5}$ concentrations in Malaysia [18]. However, when the restrictions on human activity are lifted, the concentrations of various pollutants are likely to rebound. In Shanghai, the FLR forced people stay at home and almost all activities were confined indoors. Comparisons between the three periods and with the same periods in the previous year all demonstrated that the reduced human activities and traffic observably improved air quality. However, the relative changes in different pollutants varied.

The concentration of $\mathrm{O}_{3}$ kept increasing during all three periods. This is in line with other reports on air quality changes during Covid-19 lockdowns for a total of 366 urban areas in China's mainland and for Almaty in Kazakhstan [7,19]. One reason may be that the ozone concentration varies seasonally, with the highest concentration always occurring in spring and the lowest in autumn [20]. Another reason may be that the decrease in $\mathrm{NO}_{x}$ leaves oxygen radicals available, causing urban $\mathrm{O}_{3}$ to increase [10]. We subtracted daily ozone values in the previous year from those in the study year to get daily $\mathrm{O}_{3}$ concentration change (delta values) for the three periods. Pair-wise comparison of the three delta values showed no significant differences, which suggests that the FLR did not have a significant effect on ozone concentration, and that seasonality contributed more to $\mathrm{O}_{3}$ change in the study period than human activity (Table S19). 
Spatial comparisons showed that the concentrations of pollutants diverged between the downtown area of Shanghai and the suburbs, and different pollutants diverged in different ways (Figure 4). The concentration of $\mathrm{NO}_{2}$ was always significantly higher in downtown, and the concentrations of $\mathrm{O}_{3}$ and $\mathrm{SO}_{2}$ were always significantly higher in the suburbs, while the other pollutants did not show consistent significant differences (showed differences in only one period). However, in during-FLR, the average concentrations of $\mathrm{NO}_{2}, \mathrm{SO}_{2}$, and $\mathrm{O}_{3}$ became more similar between downtown and the suburbs, as indicated by the shading in Table 3. During-FLR, city traffic ceased and industrial production was suspended, and these changes had different impacts depending on the human activities and population density concentrated in different areas of the city. In downtown Shanghai, the population density is markedly higher than in the suburbs and the numbers of private vehicles and public transportation vehicles are higher, resulting in more $\mathrm{NO}_{2}$ being emitted. The suburbs of Shanghai are home to fewer people but have more space available, so most manufacturing plants are located there. Of the top 100 manufacturing enterprises in Shanghai in 2019, 77 were located in the suburbs. These emit various polluting gases $\left(\mathrm{SO}_{2}\right.$, etc.) when in operation, but during-FLR many of these factories stopped production, explaining the different pollutant concentration changes between downtown and suburbs. Thus, the pollutants emitted from different types of human activities may differ, but a reduction in all human activities is clearly beneficial overall for urban air quality $[7,21]$.

\subsection{Management Implications}

The government of China attaches great importance to air quality, and has launched several policies for prevention and control of air pollution. Among these, the Air Pollution Prevention and Control Action Plan (known as Article 10 of the Atmosphere), which was issued in 2013 [22], has had the greatest impact. It has been reported that the concentration of fine particles $\left(\mathrm{PM}_{2.5}\right)$ in the air has shown a significant decline nation-wide as a result of the industrial emission abatements brought about by implementation of this clean air policy in China [21]. However, the effect of other human activities, such as transportation and lifestyles, on the concentration of air pollutants is still unclear. Our study showed that the FLR policy significantly improved the air quality in Shanghai by restricting the activities of urban residents, suspending the use of private cars, and shutting down factories during the pandemic. Our results have three major implications for future clean air policies in China and in other polluting countries.

First, we suggest further strengthening of central government policy on urban air quality. Unlike many other countries, China has a strong central government and can implement policy at all levels of government [23]. The nation-wide implementation of the Air Pollution Prevention and Control Action Plan has already achieved a reduction in the concentration of fine particles [21]. The FLR policy to control the spread of Covid-19 had the additional effect of improving Shanghai's air quality. However, we found that the concentrations of various pollutants are likely to rebound when the restrictions on human activities are lifted. Therefore, we suggest that the government continues to take strict control measures to ensure the safety of urban living environments.

Second, we suggest a change to a low-carbon lifestyle and consumer behavior. The low-carbon lifestyle, which is becoming very common, generally refers to a change from a former polluting living mode to a new mode that can reduce energy consumption and greenhouse gas emissions, especially carbon dioxide [24]. In the case of urban air quality, the low-carbon lifestyle refers to encouraging urban residents to use public transport and reduce their use of private cars, which can reduce the air pollutant emissions from vehicles. During the FLR in Shanghai, the use of private vehicles practically ceased and public transportation became the main traffic mode, a change that significantly improved the air quality, as shown in this study.

Third, we suggest the introduction of cleaner production in industrial enterprises. Industrial enterprises play an important role in the local economy and cannot be shut down completely. However, they could be encouraged to adopt a sustainable development path through cleaner production reforms, such as adjusting the industrial structure, technological innovation to reduce 
emissions, and establishing a strict reward and punishment system. Energy-intensive economic growth is the common development mode, but produces large amounts of pollutants, especially in industry-intensive cities like Shanghai [25]. During the FLR, most factories were closed to control the epidemic. For instance, the steel industry, which emits $\mathrm{PM}_{2.5}, \mathrm{SO}_{2}$, and $\mathrm{NO}_{\mathrm{x}}$ [26], may have reduced its emissions during the FLR period. Although different industries or enterprises emit different amounts and forms of air pollutants, the FLR resulted in a total reduction in industrial discharge of air pollutants in the case of Shanghai Municipality.

\subsection{Strengths and Limitations}

Using real air pollutant data, we identified distinct changes in air pollutant concentrations in the FLR period and demonstrated that human activities had important impacts on air quality in Shanghai. This is valuable information for policymakers in their future air quality-related work. However, the study had two main limitations, which need to be resolved in future research.

First, the causal relationships between human activities and urban air quality need to be further explored. The significant reduction in concentrations of a specific pollutant could be mainly due to vehicular traffic or industrial emissions, so their relative contributions should be further analyzed [8]. Furthermore, the effect of FLR policy on the urban heat island effect should be explored.

Second, other factors may have contributed to the improvement in air quality, such as climate change, meteorological conditions, and other periodic weather-related changes, which were not considered in the present study. For example, when meteorological conditions are unfavorable, pollutants may not disperse after production [27]. Seasonal fluctuations in air quality should also be studied [2].

\section{Conclusions}

We assessed the effect of FLR policy, introduced to control the spread of Covid-19, on air quality in Shanghai Municipality, China. The strict limitations imposed on urban residents' movements and activities during the lockdown period resulted in a significant reduction in the concentration of all key air pollutants tested except $\mathrm{O}_{3}$. This reduction was most likely due to the reduction in vehicular traffic and industrial emissions. However, the concentrations of pollutants rebounded gradually when the restrictions on human activities were lifted. Promoting the forms of human activity behind the air quality improvement should be considered a priority in future urban management. However, human activities can differ between cases, so the causal relationships between human activities and air quality should be further explored.

This study provides empirical evidence of the positive impact of FLR policy in improving urban air quality. To achieve sustainable and clean future urban environments, central government policy on air quality improvement should be strengthened, and a low-carbon lifestyle and cleaner production in industrial enterprises should be implemented. If properly designed, such a policy can achieve a win-win between sustainable urban development and appropriate human activities.

Supplementary Materials: The following are available online at http://www.mdpi.com/2071-1050/12/21/8887/s1.

Author Contributions: Funding acquisition, Y.B.; Resources, Y.B.; Writing-original draft, Y.Z.; Writing一review \& editing, Y.B., J.M.A. and A.C.H. All authors have read and agreed to the published version of the manuscript.

Funding: This study was supported by the West Light Talent Program of the Chinese Academy of Sciences (Grant No. Y9XB011B01) and the Key Research Program of Frontier Sciences (Grant No. ZDBS-LY-7011); JMA was supported by Qatar Petroleum.

Conflicts of Interest: The authors declare no conflict of interest. 


\section{References}

1. Li, J.; Fang, W.; Wang, T.; Qureshi, S.; Alatalo, J.M.; Bai, Y. Correlations between Socioeconomic Drivers and Indicators of Urban Expansion: Evidence from the Heavily Urbanised Shanghai Metropolitan Area, China. Sustainability 2017, 9, 1199. [CrossRef]

2. Mahato, S.; Pal, S.; Ghosh, K.G. Effect of lockdown amid COVID-19 pandemic on air quality of the megacity Delhi, India. Sci. Total. Environ. 2020, 730, 139086. [CrossRef] [PubMed]

3. Franco, J.F.; Gidhagen, L.; Morales, R.; Behrentz, E. Towards a better understanding of urban air quality management capabilities in Latin America. Environ. Sci. Policy 2019, 102, 43-53. [CrossRef]

4. Zhou, Z.; Chen, Y.; Song, P.; Ding, T. China's urban air quality evaluation with streaming data: A DEA window analysis. Sci. Total Environ. 2020, 727, 138213. [CrossRef]

5. Goyal, P. Present scenario of air quality in Delhi: A case study of CNG implementation. Atmos. Environ. 2003, 37, 5423-5431. [CrossRef]

6. Gulia, S.; Mittal, A.; Khare, M. Quantitative evaluation of source interventions for urban air quality improvement-A case study of Delhi city. Atmos. Pollut. Res. 2018, 9, 577-583. [CrossRef]

7. Kerimray, A.; Baimatova, N.; Ibragimova, O.P.; Bukenov, B.; Kenessov, B.; Plotitsyn, P.; Karaca, F. Assessing air quality changes in large cities during COVID-19 lockdowns: The impacts of traffic-free urban conditions in Almaty, Kazakhstan. Sci. Total. Environ. 2020, 730, 139179. [CrossRef]

8. Collivignarelli, M.C.; Abbà, A.; Bertanza, G.; Pedrazzani, R.; Ricciardi, P.; Miino, M.C. Lockdown for CoViD-2019 in Milan: What are the effects on air quality? Sci. Total. Environ. 2020, 732, 139280. [CrossRef]

9. Wang, Q.; Su, M. A preliminary assessment of the impact of COVID-19 on environment-A case study of China. Sci. Total. Environ. 2020, 728, 138915. [CrossRef]

10. Tobías, A.; Carnerero, C.; Reche, C.; Massagué, J.; Via, M.; Minguillón, M.C.; Alastuey, A.; Querol, X. Changes in air quality during the lockdown in Barcelona (Spain) one month into the SARS-CoV-2 epidemic. Sci. Total. Environ. 2020, 726, 138540. [CrossRef]

11. Statistical Bulletin of Shanghai Municipality on National Economic and Social Development (SBS). Shanghai Bureau of Statistics. 2019. Available online: http://tj.sh.gov.cn (accessed on 9 March 2020).

12. Chen, J.; Jiang, B.; Bai, Y.; Xu, X.; Alatalo, J.M. Quantifying ecosystem services supply and demand shortfalls and mismatches for management optimisation. Sci. Total. Environ. 2019, 650, 1426-1439. [CrossRef]

13. Shanghai Ecological and Environmental Bulletin (SEEB). Shanghai Municipal Bureau of Ecology and Environment. 2019. Available online: https://sthj.sh.gov.cn (accessed on 4 June 2020).

14. Ambient Air Quality Standards. Ministry of Ecology and Environment of the People's Republic of China. 2012. Available online: http://www.mee.gov.cn (accessed on 1 January 2016).

15. Leogrande, S.; Alessandrini, E.R.; Stafoggia, M.; Morabito, A.; Nocioni, A.; Ancona, C.; Bisceglia, L.; Mataloni, F.; Giua, R.; Mincuzzi, A.; et al. Industrial air pollution and mortality in the Taranto area, Southern Italy: A difference-in-differences approach. Environ. Int. 2019, 132, 105030. [CrossRef]

16. Cheung, C.W.; He, G.; Pan, Y. Mitigating the air pollution effect? The remarkable decline in the pollution-mortality relationship in Hong Kong. J. Environ. Econ. Manag. 2020, 101, 102316. [CrossRef]

17. Nakada, L.Y.K.; Urban, R.C. COVID-19 pandemic: Impacts on the air quality during the partial lockdown in São Paulo state, Brazil. Sci. Total. Environ. 2020, 730, 139087. [CrossRef] [PubMed]

18. Abdullah, S.; Abu Mansor, A.; Napi, N.N.L.M.; Mansor, W.N.W.; Ahmed, A.N.; Ismail, M.; Ramly, Z.T.A. Air quality status during 2020 Malaysia Movement Control Order (MCO) due to 2019 novel coronavirus (2019-nCoV) pandemic. Sci. Total. Environ. 2020, 729, 139022. [CrossRef]

19. Wang, Y.; Yuan, Y.; Wang, Q.; Liu, C.; Zhi, Q.; Cao, J. Changes in air quality related to the control of coronavirus in China: Implications for traffic and industrial emissions. Sci. Total. Environ. 2020, 731, 139133. [CrossRef] [PubMed]

20. Zheng, W. Taiyuan city environment variation characteristics of ozone concentration in the air. Mod. Chem. Res. 2016, 10, 63-64.

21. Zhang, Q.; Zheng, Y.; Tong, D.; Shao, M.; Wang, S.; Zhang, Y.; Xu, X.; Wang, J.; He, H.; Liu, W.; et al. Drivers of improved PM2.5 air quality in China from 2013 to 2017. Proc. Natl. Acad. Sci. USA 2019, 116, 24463-24469. [CrossRef]

22. China State Council. Air Pollution Prevention and Control Action Plan (ACP); China State Council: Beijing, China, 2013; Volume 9, p. 10. 
23. Bai, Y.; Wong, C.P.; Jiang, B.; Hughes, A.C.; Wang, M.; Wang, Q. Developing China's Ecological Redline Policy using ecosystem services assessments for land use planning. Nat. Commun. 2018, 9, 1-13. [CrossRef]

24. Schanes, K.; Giljum, S.; Hertwich, E. Low carbon lifestyles: A framework to structure consumption strategies and options to reduce carbon footprints. J. Clean. Prod. 2016, 139, 1033-1043. [CrossRef]

25. Liu, X.-J.; Xia, S.-Y.; Yang, Y.; Wu, J.-F.; Zhou, Y.-N.; Ren, Y.-W. Spatiotemporal dynamics and impacts of socioeconomic and natural conditions on PM2.5 in the Yangtze River Economic Belt. Environ. Pollut. 2020, 263, 114569. [CrossRef] [PubMed]

26. Yang, H.; Tao, W.; Liu, Y.; Qiu, M.; Liu, J.; Jiang, K.; Yi, K.; Xiao, Y.; Tao, S. The contribution of the Beijing, Tianjin and Hebei region's iron and steel industry to local air pollution in winter. Environ. Pollut. 2019, 245, 1095-1106. [CrossRef] [PubMed]

27. Wang, P.; Chen, K.; Zhu, S.; Wang, P.; Zhang, H. Severe air pollution events not avoided by reduced anthropogenic activities during COVID-19 outbreak. Resour. Conserv. Recycl. 2020, 158, 104814. [CrossRef] [PubMed]

Publisher's Note: MDPI stays neutral with regard to jurisdictional claims in published maps and institutional affiliations.

(C) 2020 by the authors. Licensee MDPI, Basel, Switzerland. This article is an open access article distributed under the terms and conditions of the Creative Commons Attribution (CC BY) license (http://creativecommons.org/licenses/by/4.0/). 